\title{
Malaysian Based Manufacturing Firms' Strategic Sourcing: A Test of Transaction Cost Economics Theory and Resource Based View
}

\author{
Haim Hilman and Ari Warokka \\ College of Business, Universiti Utara Malaysia, Malaysia
}

\begin{abstract}
The relentless searching of strategic sourcing, due to the fact that globalization is inevitable and today's manufacturers are competing in highly competitive environment, has pooled many business practices into two competing school of thoughts related to sourcing strategies, i.e. Transaction Cost Economics (TCE) Theory and Resource Based View (RBV). This paper explored sourcing strategies and sourcing supplying countries of firms in Malaysia in responding to the intensified competition and put these strategies as an integral parts of firms' distinctive competencies. Specifically, the results indicated sourcing strategies have significant effects to both financial and non-financial performance. However, both models indicated the 'self-produce' and 'outsourcing' strategies affect non-financial performance more than financial performance. The results also indicated the most popular supplying countries for both sourcing strategies (selfproduce and outsourcing) are Malaysia, China and Singapore and the majority of them received supply from one country. These findings provide new insights of sourcing practices among Malaysia based manufacturing firms and how those companies perceive and react to the competition environment surrounding them.
\end{abstract}

Keywords: Sourcing Strategies, Self-produce, Outsourcing, Performance

\section{Introduction}

Manufacturing based firms face challenges on a variety of fronts. Today's competition is highly competitive if compared to 20 years ago. In other words, technological advancement is happening every second and around the globe. There is no guarantee that today's leading firm will retain its position tomorrow. All these rewrite the rules of the game as more is demanded than ever before. In response to these demands, more and more manufacturing based firms pursue continuous improvement, leaned up production, reengineered business processes and integrated supply chains.
Over the past decade, there has been a growing realisation on the importance of purchasing and supply management (Cousins, Lawson, \& Squire, 2006) on organizational performance. Both academics and practitioners agree on the importance of sourcing strategy and its role in enhancing competitiveness of firms. Global deregulation in many industries also leads to the standardization of business practices and the increase of co-operation between customers, suppliers and other stakeholders (Ranky, 2007). The World Trade Organization (WTO), ASEAN Free Trade Area (AFTA), Free Trade Agreement (FTA), and North America Free Trade Area (NAFTA) are among most widely

Copyright (C) 2011 Haim Hilman and Ari Warokka. This is an open access article distributed under the Creative Commons Attribution License unported 3.0, which permits unrestricted use, distribution, and reproduction in any medium, provided that original work is properly cited. Contact author: Haim Hilman e-maill: hilman@uum.edu.my 
cited forces that shape today's business practices (Hilman, 2010).

This study specifically investigated sourcing practices of manufacturing based firms in Malaysia. Firms that were referred to as using a self-produce strategy are firms that produced $51 \%$ or more of their products' components. Meanwhile, outsourcing strategy refer to firms that bought $51 \%$ or more of their products' components.

\section{Literature Review}

\section{Sourcing Strategy}

Market globalization or borderless world phenomenon is driving firms to put greater emphasis on sourcing practices (Branemo, 2006). One of the earliest typologies examining purchasing function configurations was developed in 1998 by Reck and Long. The typology consists of four stages of purchasing development from passive, independent, supportive to integrative.

Since then sourcing has become an important factor for firms to gain advantage over competitors (Kemppainen \& Vepsalainen, 2003) and a key factor in enhancing firms' competitiveness and organizational performances (Fantazy, Kumar \& Kumar, 2009). More and more firms became very critical in determining sourcing strategies between self-produce versus outsourcing that are both strongly related to the Transaction Cost Economics (TCE) and Resource Based View (RBV) (Wei \& Chen, 2008).

Historical events like the 1970s' Arab-oil embargo in the USA have made firms recognize strategic role of sourcing and turned sourcing unimportant or clerical function to a highly skilled strategic function and component of strategic planning (Branemo, 2006). The recognition is even greater now as many leading firms have considered control cost and supply management as important factors in maintaining competitiveness (Fantazy et al., 2009).

\section{Self-Produce}

Capron and Mitchell (2004) argue that selfproduce and outsourcing strategies present differences in their capacity to cope with contractual hazards, strategic gaps and internal legitimacy difficulties. Based on the transaction cost arguments, managers are more likely to choose self-produce over outsourcing when the targeted capabilities face increasing asset specificity and contractual hazards (Watson, 2004).

Generally, firms opt for self-produce strategy when targeted capabilities do not exist outside the firm or even if they do exist, they cannot be traded through markets or across firms (Capron \& Mitchell, 2004), or when suppliers do not want to trade unique and valuable resources (Dierickx \& Cool, 1989). Therefore, to remain competitive requires firms to develop the ability to recombine internal capabilities into new configurations (Galunic \& Rodan, 1998).

Such approach is based on the RBV where firms seek unique or otherwise costly-tocopy inputs. For example, Barney (1986) argues that organizational culture can be leveraged for superior performance because it is rare and difficult to imitate. This notion applies directly to the challenge of appropriation of new technology benefits. High technology oriented firms invest more in building technical capabilities besides allocating scarce resources in a very specific way and always consistent with their core strategies (Barney, 1986). The RBV logic predicts that activities will be outsourced when suppliers possess superior knowledge only (Kogut \& Zander, 1996).

\section{Outsourcing}

Outsourcing can be defined as an act of moving some of a firm's internal activities and decision responsibilities to outside providers (Chase, Jacobs \& Aquilano, 2004). 
Nowadays more and more firms contract out significant percentage of their manufacturing and service activities than they did two decades ago (Hilman, 2010). This trend is due to changes in the business environment and the pursuit of lean operations (Hui \& Tsang, 2004).

Despite the advantages, there are disadvantages in adopting outsourcing such as making firms too dependent on outside suppliers, failure to realise the purported hidden cost saving to outsourcing, losing control over critical functions and lowering the morale of permanent employees (Tsai, Liao \& Han, 2008). Poor observation on advantages and disadvantages of outsourcing may put respective firms' competitiveness at stake (Hilman, 2010).

The root of outsourcing is based on Williamson (1975), which was inspired by Coase (1937) and Arrow (1962). Firms adopting this strategy are driven by transaction cost economics (TCE) and intention to minimize costs or costs due to organizational hierarchy. The central question of TCE is still whether a transaction is more efficiently performed within firm or by outsourcing it, by autonomous contractors (Geykens, Steenkamp \& Kumar, 2006).

\section{Sourcing Strategies and Performance Link}

There is no doubt on the importance of sourcing issue in manufacturing strategy (Mclvor \& Humphreys, 2000). The sourcing decision has been recognized by practitioners as one of major determinants contributing to the financial health of firms (Zeng, 2000; Cousins et al., 2006). Interestingly, the interest in conducting researches on sourcing decisions can be traced to the era of the 1930s (Park, Reddy \& Sarkar, 2000).

Issue of self-produce or outsourcing remains as one of the most strategic issues to most firms. Most scholars agree that core activities should stay in-house, whilst non-core activities can be outsourced (Mullin, 1996).
Interestingly, several empirical researches indicated that outsourcing is not used for support services or non-core activities only but activities 'closer to core' (Harland, Lamming \& Walker, 2005).

However, it is risky to focus solely on costs because such performance assessment might lead managers to ignore other strategic objectives (Karsak \& Tolga, 2001; Morgan \& Daniels, 2001). Over the last ten years, many authors have suggested that performance measurement should comprise both financial and non-financial measurement tests (Venkatraman and Ramanujam, 1986; Lee and Miller, 1996; Kaplan \& Norton, 1996).

This study adopted performance measurements that were used widely in business whereas consisting of both financial and strategic performance (Kaplan \& Norton, 1996). The dimensions representing the organizational performance (dependent variable) are: (1) return on sales (ROS), (2) return on investment (ROI), (3) market share, (4) sales growth rate, (5) innovation and learning perspective, (6) customer perspective, and (7) internal business perspective.

\section{Research Methodology}

Data for this study was collected using a mail survey approach. A set of questionnaires were sent out to 1300 firms (total population) and 314 or $24 \%$ of them responded. Specifically one set of questionnaire was sent out to individual holding senior position (e.g. CEO, Managing Director, and General Manager) of firms listed in the Federation of Malaysian Manufacturers (FMM).

The questionnaires were adopted from previous researches. For sourcing strategies, the instruments have twelve questions, which were adopted from Kotabe and Omura (1989). For the organizational performance, the instruments combined both financial and non-financial measurement instruments. Specifically, it consists of seven 
questionnaires which were adopted from Venkatraman and Ramanujam, (1986); Lee and Miller, (1996); and Kaplan and Norton (1996). Specifically this study addressed the following questions:

- Which sourcing strategies are used the most by manufacturing based firms in Malaysia?

- Where are the supplying countries?

- Which one of the sourcing strategies affects financial and non-financial most?

- How significant does the 'self-produce' and 'outsourcing' strategies affect performance?

Besides that, this study also addressed the following hypotheses.

- Hypothesis 1: Self-produce strategy effects organizational performance

- Hypothesis 2: Outsourcing strategy effects organizational performance

This study defines a firm sourcing strategy using the percentage of components of its major product that was self produced or outsourced. If majority of the components or $51 \%$ were for self-produce then the company is categorized as using self-produce strategy and vice versa.

\section{Findings}

\section{Sourcing Strategy Preferences among Respondents}

For the continuous variable (percentage) of sourcing strategy, the outsourcing strategy was found the most popular option of the two with $51.27 \%$ of the respondents opted for this strategy. This means the remaining respondents or $48.73 \%$ used the selfproduce strategy.

The result clearly indicated that most of manufacturing based firms in Malaysia adopted both strategies. This means no clear preferences and differences between the two strategies. This finding does not go along fully with present trend on today's sourcing strategy that is clearly inclined towards outsourcing strategy.

\section{Distribution of Supplying Countries (Self- produce\& Outsourcing)}

Out of four groups of supplying countries, the self-produce strategy oriented firms' were relying on one and more than one supplying country. Specifically, $49.67 \%$ rely on supplier from one country, $26.79 \%$ from two countries, $10.46 \%$ from three countries and $13.08 \%$ from four countries. Meanwhile, for the outsourcing strategy oriented firms; $19.25 \%$ received supply from one country, $19.88 \%$ from two countries, $44.72 \%$ from three countries and $16.15 \%$ from four countries.

Distribution of Supplying Countries (Selfproduce strategy)

The top ten or most popular supplying country for firms opted self-produce strategy was Malaysia (18.79\%) and followed by China (4.14\%), Singapore (3.26\%), Indonesia (3.03\%), Thailand (2.31\%), Japan (1.67\%), USA (1.18\%), UK (1.04\%), Germany (0.96\%), and Vietnam (0.96\%). The option for 'others' consists of many countries with small percentage. (see Table 1). 
5 Journal of Outsourcing and Organizational Information Management

Table 1: Top 10 Supplying Countries for Self-produce Strategy

\begin{tabular}{|c|c|c|c|c|c|c|c|}
\hline No & Country & $\begin{array}{c}\text { Opt } \\
1\end{array}$ & Opt 2 & $\begin{array}{c}\text { Opt } \\
3\end{array}$ & $\begin{array}{c}\text { Opt } \\
4\end{array}$ & $\begin{array}{c}\text { Frequenc } \\
\mathbf{y}\end{array}$ & $\begin{array}{c}\text { Percentage } \\
\%\end{array}$ \\
\hline 1. & Malaysia & 227 & - & 9 & - & 236 & 18.79 \\
\hline 2. & China & 6 & 31 & 15 & - & 52 & 4.14 \\
\hline 3. & Singapore & 15 & 23 & 3 & - & 41 & 3.26 \\
\hline 4. & Indonesia & 24 & 9 & 5 & - & 38 & 3.03 \\
\hline 5. & Thailand & 3 & 23 & 2 & 1 & 29 & 2.31 \\
\hline 6. & Japan & 12 & 3 & 6 & - & 21 & 1.67 \\
\hline 7. & USA & 6 & - & 9 & - & 15 & 1.18 \\
\hline 8. & UK & 3 & 10 & - & - & 13 & 1.04 \\
\hline 9. & Germany & 3 & 6 & 3 & - & 12 & 0.96 \\
\hline 10. & Vietnam & - & 7 & 4 & 1 & 12 & 0.96 \\
\hline 11. & Others & 15 & 202 & 258 & 312 & 787 & 62.66 \\
\hline & Total & 314 & 314 & 314 & 314 & 1256 & 100.00 \\
\hline
\end{tabular}

The results clearly indicate that most manufacturing based firms in Malaysia that opted for self-produce strategy get supply from local suppliers. Next popular sourcing countries are ASEAN countries as three of them listed among top five supplying countries besides China. These finding shows that most firms in this category benefited from the AFTA and ASEAN - China FTA agreements.

\section{Distribution of Supplying Countries (Outsourcing Strategy)}

For the outsourcing strategy, the top ten most popular country for firms opted for outsourcing strategy was Malaysia (13.77\%) and followed by China (7.32\%), Singapore (4.38\%), Japan (3.50\%), USA (3.26\%), Germany (2.63\%), South Korea (2.31\%), Thailand (2.23\%), Indonesia (1.91\%), and UK $(1.27 \%)$. Meanwhile the option for 'others' consists of many countries with small percentage. (see Table 2). 
Table 2: Top 10 Supplying Countries for Outsourcing Strategy

\begin{tabular}{llrrrrcc}
\hline No. & Country & $\mathbf{0 p t}$ & $\mathbf{0 p t}$ & $\mathbf{0 p t}$ & $\mathbf{0 p t}$ & $\begin{array}{c}\text { Frequenc } \\
\mathbf{2}\end{array}$ & $\begin{array}{c}\text { Percentage } \\
\mathbf{2}\end{array}$ \\
\hline 1. & Malaysia & 137 & 16 & \multicolumn{1}{c}{18} & 2 & 173 & 13.77 \\
2. & China & 43 & 39 & 10 & - & 92 & 7.32 \\
3. & Singapore & 37 & 12 & 6 & - & 55 & 4.38 \\
4. & Japan & 13 & 21 & 10 & - & 44 & 3.50 \\
5. & USA & 17 & 15 & 9 & - & 41 & 3.26 \\
6. & Germany & 16 & 9 & 8 & - & 33 & 2.63 \\
7. & South & 3 & 17 & 9 & - & 29 & 2.31 \\
8. & Korea & & & & & & \\
9. & Inailand & 9 & 14 & 5 & - & 28 & 2.23 \\
10. & UK & 7 & 3 & 6 & - & 16 & 1.91 \\
11. & Others & 20 & 157 & 232 & 312 & 721 & 57.42 \\
\hline & Total & $\mathbf{3 1 4}$ & $\mathbf{3 1 4}$ & $\mathbf{3 1 4}$ & $\mathbf{3 1 4}$ & $\mathbf{1 2 5 6}$ & $\mathbf{1 0 0 . 0 0}$ \\
\hline
\end{tabular}

The findings also indicate that Malaysia is the most popular sourcing country for firms that opted for the outsourcing strategy. The second and third most popular supplying countries were China and Singapore. However, for rank fourth and fifth were not ASEAN countries but Japan and USA respectively. These show firms that opted for this strategy more advanced and aggressive than its counterparts that opted for selfproduce strategy in seeking best source of supply.

\section{Self-produce Strategy and Effects on Financial and Non-Financial Performance}

Path analysis was conducted to describe the effect of the self-produce strategy (independent variable) on financial and nonfinancial performance (dependent variable). The results indicate regression coefficients are significantly different from zero and beyond 0.01 levels. This indicates a positive relationship exists between the 'self-produce strategy' and the 'financial and non financial performance'.

The standardized estimates show the relative contributions of each predictor variable to each outcome variable. This means when the 'self-produce strategy' goes up by one standard deviation then the financial performance goes up by 0.33 of standard deviation and when the 'self-produce strategy' goes up by one standard deviation then the non-financial performance goes up by 0.36 of standard deviation. This means the 'self-produce strategy' has higher impact on 'non-financial performance' than the 'financial performance'.

\section{Outsourcing Strategy and Effects on Financial and Non-Financial Performance}

Similar findings were identified for the relationship between 'outsourcing strategy' and 'financial and non financial performances' as regression coefficients significantly different from zero and beyond 0.01 levels. The results indicate that a positive relationship exists between the 'outsourcing strategy' and the 'financial and non financial performance'. The standardized estimates show the relative contributions of each predictor variable to each outcome variable. When the 'outsourcing strategy' goes up by one standard deviation then the financial performance goes up by 0.21 of 
standard deviation and when the 'outsourcing strategy' goes up by one standard deviation then the non-financial performance goes up by 0.39 of standard deviation. Specifically the 'outsourcing strategy' has higher impact on the 'nonfinancial performance' than the 'financial performance'.

Measuring Degree of Influence of SelfProduced Strategy on Organizational Performance

Hypothesis 1: Self-produce strategy effects organizational performance

A linear regression analysis was conducted to evaluate the prediction of the 'self-produce strategy' from the 'organizational performance'. The result indicates the two variables have positive relationship; $R^{2}=$ 0.154 , Adj. $R^{2}=0.149$, and $F(1,151)=$ $27.585, \mathrm{p}<0.05$. The $\mathrm{R}^{2}$ means that $15 \%$ of the variance in the organizational performance increase was explained by the self-produce strategy. Approximately, $15 \%$ of the variance of the organizational performance is accounted for by its linear relationship with the self-produce strategy. Support Hypothesis 1: Self-produce strategy effects organizational performance. The regression regression equation for predicting the organizational performance is:

$$
\begin{gathered}
\text { Regression Equation }(y)=a+b x+e \\
\begin{array}{c}
\text { Performance }=3.790+0.349 \\
\text { produce strategy) }+e
\end{array}
\end{gathered}
$$

\section{Measuring Degree of Influence of Outsourcing Strategy on Organizational Performance}

Hypothesis 2: Outsourcing strategy effects organizational performance

A linear regression analysis that was conducted to evaluate the prediction of the outsourcing strategy from the organizational performance indicates that the two variables have positive relationship; $R^{2}=0.145$, Adj. $R^{2}$
$=0.139$, and $F(1,159)=26.926, p<0.01$. The $\mathrm{R}^{2}$ means that $15 \%$ of the variance in the 'organizational performance' increase was explained by the outsourcing strategy. Approximately, $15 \%$ of the variance of the organizational performance is accounted for by its linear relationship with the outsourcing strategy. Support Hypothesis 2: Self-produce strategy effects organizational performance. The regression equation for predicting the organizational performance is:

$$
\begin{gathered}
\text { Regression Equation }(y)=a+b x+e \\
\text { Performance }=3.496+0.409 \\
\text { (Outsourcing strategy) }+e
\end{gathered}
$$

Both hypotheses 1 and 2 produced similar results. This means sourcing strategies are important and play significant role in determining financial and non-financial performances of firms.

\section{Discussion and Conclusions}

The study confirms the importance of sourcing strategy to Malaysia's manufacturing firms. The findings recognized sourcing as another strategic issue in modern business management. It indicated that $51.27 \%$ of firms in Malaysia opted for 'outsourcing strategy' while $48.73 \%$ opted for 'self-produce' strategy. Specifically the most popular supplying countries for firms opted for the 'self-produce strategy' was Malaysia (18.79\%), China (4.14\%) and Singapore (3.26\%). Similar preferences occurred for the 'outsourcing strategy', which Malaysia $(13.77 \%)$ was ranked first and followed by China (7.32\%) and Singapore (4.38\%).

The findings analysis indicated Hypothesis 1 and 2 indicate positive relationship between the independent variable and independent variables. Hypothesis 1 indicates to describe positive relationship exists between the 'selfproduce strategy' and the 'financial performance' as well as between the 'selfproduce strategy' and the 'non-financial performance'. Similar findings for Hypothesis 
2 as the result indicate positive relationship between the 'outsourcing strategy' and the 'financial performance' as well as between the 'outsourcing strategy' and the 'nonfinancial performance'. Specifically both models indicate that the 'self-produce' and 'outsourcing' strategies affect 'non-financial performance' more than the financial performance. These findings go along with the literature that self-produce and outsourcing strategies are determinants of profit making or financial health of firms (Yoon \& Naadimuthu, 1994; McIvor \& Humphreys, 2000; Zeng, 2000; Cousins et al., 2006).

In conclusion, managers could make better decisions in the context of determining sourcing destinations, options (self-produce and outsourcing). However, several opportunities for future research exist. For example, given the dearth of studies relating to sourcing firms in Malaysia, further investigation including other sectors and countries would assist with our understanding of generalising these results. In addition, other aspects of the sourcing model should examine to understand the mediating or moderating relationship between sourcing strategy and performance.

\section{References}

Arrow, K. J. (1962). "Economic Welfare and the Allocation of Resources for Invention," the Rate and Direction of Inventive Activity. Princeton University Press, Princeton, NJ, 353-8.

Barney, J. B. (1986). Organizational Culture: Can it Be a Source of Sustained Competitive Advantage?," Academy of Management Review, 11 (3), 656-65.

Branemo, A. (2006). "How Does the Industry Work with Sourcing Decisions? Case Study at Two Swedish Companies," Journal of Manufacturing Technology Management, 17(5), 547-560.
Capron, L. \& Mitchell, W. (2004). "Where Firms Change: Internal Development Versus External Capability Sourcing in the Global Telecommunication Industry," European Management Review, Winter, 1 (2), 157.

Chase, R. B., Robert, J. F. \& Aquilano, N. J. (2004). Operations Management for Competitive Advantage, 10th Edition. McGraw-Hill, Boston, MA.

Coase, R. H. (1937). "The Nature of the Firm," Economica N.S., 4, 386-405.

Cousins, P. D. (2005). "The Alignment of Appropriate Firm and Supply Strategies for Competitive Advantage," International Journal of Operations \& Production Management, 25 (5), 403-28.

Cousins, P. D., Lawson, B. \& Squire, B. (2006). "An Empirical Taxonomy of Purchasing Functions," International Journal of Operations \& Production Management, 26 (7), 775-794.

Dierickx, I. \& Cool, K. (1989). "Asset Stock Accumulation and Sustainability of Competitive Advantage, Reply," Management Science, 35: 1504-1513.

Fantazy, K. A., Kumar, V. \& Kumar, U. (2009). "An Empirical Study of the Relationships among Strategy, Flexibility, and Performance in the Supply Chain Context," Supply Chain Management: An International Journal, 14(3), 177-188.

Galunic, D. C. \& Rodan, S. (1998). "Resource Re-combinations in the Firm: Knowledge Structures and the Potential for Schumpetarian Innovation," Strategic Management Journal, 19, 1193-1201.

Geykens, I., Steenkamp, J. E. M. \& Kumar, N. (2006). "Make, Buy, or Ally: A Transaction Cost Theory Meta-Analysis," Academy of Management Journal, 49(3), 519-543.

Ghalayini, A. M. \& Noble, J. S. (1996). "The Changing Basis of Performance Measurement," International Journal of 
9 Journal of Outsourcing and Organizational Information Management

Operations \& Production Management, 16(8), 63-80.

Harland, C., Knight, L., Lamming, R. \& Walker, H. (2005). "Outsourcing: Assessing the Risks and Benefits for Organisations, Sectors and Nations," International Journal of Operations \& Production Management, 25(9), 831-850.

Hilman, H. (2010). Strategic Management, 3rd Ed., Pearson-Prentice Hall

Hui, E.Y.Y. \& Tsang, A. H. C. (2004). "Sourcing Strategies of Facilities Management," Journal of Quality in Maintenance Engineering, 10(2), 85-92.

Kaplan, R. S. \& Norton, D. P. (1996). "Using the Balanced Scorecard as a Strategic Management System," Harvard Business Review, 74(1), 75-85.

Karsak, E. E. \& Tolga, E. (2001). "Fuzzy MultiCriteria Decision Making Procedure for Evaluating Advanced Manufacturing System Investments," International Journal of Production Economics, 69(1), 49-64.

Kemppainen, K. \& Vepsalainen, A. P. J. (2003). "Trends in Industrial Supply Chains and Networks," International Journal of Physical Distribution \& Logistic Management, 33(8), 701-719.

Kogut, B. \& Zander, U. (1996). "What Firms Do? Coordination, Identity, and Learning," Organization Science, 7, September-October, 383-97.

Kotabe, M. \& Omura, G. S. (1989). "Sourcing Strategies of European and Japanese Multinationals: A Comparison," Journal of International Business Studies, 113-130.

Lee, J. \& Miller, D. (1996). "Strategy, Environment and Performance in Two Technological Contexts: Contingency Theory in Korea," Organization Studies, 17, 729-750.

McIvor, R.T. \& Humphreys, P. K. (2000). "A Case-Based Reasoning Approach to the Make or Buy Decision," Integrated Manufacturing Systems, 11 (5), 295-310.
Morgan, L. O. \& Daniels, R. L. (2001). "Integrating Product Mix and Technology Adoption Decisions: A Portfolio Approach T Adoption of Advanced Manufacturing Technologies in the Automobile Industry," Journal of Operations Management, 19(2), 219-38.

Mullin, R. (1996). "Managing the Outsourced Enterprise," Journal of Business Strategy, $17(4), 28-32$.

Park. H.Y., Reddy, C. S. \& Sarkar, S. (2000). 'Make or Buy Strategy of Firms in the U.S,' Multinational Business Review, Fall, 8(2), 89.

Ranky, P. G. (2007). "Eighteen "MonozukuriFocus" Assembly Line Design and Visual Factory Management with DENSO Industrial Examples," Assembly Automation, 27(1), 1216.

Reck, R. F., \& Long, B. G. (1988). 'Purchasing: A Competitive Weapon,' Journal of Purchasing and Materials Management, 24(3), 1-12.

Tsai, M.-C., Liao, C.-H. \& Han, C.-S. (2008). "Risk Perception on Logistics Outsourcing of Retail Chain: Model Development and Empirical Verification in Taiwan," Supply Chain Management: An International Journal, 13(6), 415-424.

Venkatraman, N. \& Ramanujam, V. (1986). "Measurement of Organizational Performance in Strategy Research: A Comparison of Approaches," Academy of Management Review, 11 (4), 801-814

Watson, G. (2004). "Uncertainty and Contractual Hazard in the Film Industry: Managing Adversarial Collaboration with Dominant Suppliers," Supply Chain Management: An International Journal, 9(5), 402-409.

Wei, C.-M. \& Cheng, C.-Y. (2008). "An Empirical Study of Purchasing in an Automotive Industry," Industrial Management \& Data Systems, 108(7), 973987. 
Williamson, O. E. (1975). Markets and Hierarchies, Analysis and Antitrust Implications: A Study in the Economics of Internal Organization, Free Press, New York, NY

Zeng A. Z., (2000). "A Synthetic Study of Sourcing Strategies," Industrial Management \& Data Systems, 100/5, 219-226. 